\section{Workfare and the medical humanities: a response to Lynne Friedli and Robert Stearn}

\author{
Sarah Atkinson
}

Interdisciplinary engagements of medical humanities have done much to expand our understanding of ill-health and the promotion of good health beyond the purview of a biomedical gaze. Nonetheless, the field has tended predominantly to speak back to the practices of medicine and the policies of public health. The emergence of a 'critical' medical humanities that is reflected through the papers in this special issue opens a broader field of enquiry that can interrogate how those mobilisations of evidence, practice and therapy inherent to a biomedical gaze infuse and inform aspects of life well beyond the formal reach of the health sector. Such aspects include the social norms that shape our understanding of ourselves and where we locate responsibility for our bodies and our lives, which, in this powerful paper by Lynne Friedli and Robert Stearn, ${ }^{1}$ include the self-management of attitudes constituting a distinctive politics of personality and well-being.

Well-being is one of those terms, like motherhood and apple pie, imbued with a sense of being always and uncontestably a good thing, a condition of some sort that is inherently the desire and pursuit of humanity. The last decade has witnessed a rapid growth of policy interest in well-being, reflected in moves by governments and international agencies to define, measure and monitor the well-being of their populations or constituencies. ${ }^{2-4}$ As such, wellbeing is mobilised as the proper end-point of policy and the marker of social progress. Well-being is treated as an individual state of being but one which, comprising material and psychological elements, is both objectively and subjectively defined and is historically and contextually specified. However, academic, policy and popular imaginaries increasingly place well-being as synonymous with a range of positive affects including happiness, confidence and self-worth. And as Friedli and Stearn demonstrate, we see

Correspondence to Professor Sarah Atkinson, Centre for Medical Humanities and Department of Geography, Lower Mountjoy, Durham University, Durham DH1 3LE, UK; s.j.atkinson@durham.ac.uk a further shifting of the mobilisation of wellbeing and positive affect to become individualised and a process factor influencing other desirable policy goals.

The shift is subtle but crucial. Positioning well-being and positive affect as a policy outcome or end-point demands attention to determinants from different scales and sites, to structural inequalities and to situated discriminations. Treating well-being and positive affect as processes towards other outcomes radically repositions responsibility for a range of desirable policy goals away from the collective, the polity and the material and onto the individual, his or her willingness and skills for self-management. Friedli and Stearn document how a mobilisation of positive psychology impacts on those already disadvantaged in access to society's resources and explicitly expose the political weight of such mobilisation in the context of contemporary neoliberalism. A policy which insists that those going through difficulties, such as unemployment, must be responsible for their own recovery shifts the scale of responsibility away from the long-term roots of social disadvantage and structural inequalities and ignores the more immediate temporal and spatial influences on those difficulties, such as recession and local labour markets. Perhaps most insidiously, this practice promotes a vision of a meritocratic society with its subsequent logic that none of us need to take responsibility for others.

The quotations from those in unemployment and seeking benefits expose the coercion they experience to perform prescribed attitudes and deportment in order to survive in the benefit system. The practice reveals a profound contradiction at the heart of government policy on well-being in whether it is to be positioned as process or as outcome. The practice of 'psychocompulsion' on those already experiencing vulnerability and loss of power is described by Friedli and Stearn from a study in the UK where the public sector model of welfare is one in which the need for welfare is seen as a state of exception. This may suggest that such 'psycho-compulsion' is bounded and contained within the enclave of welfare and limited to those seeking benefits and hardship relief, but this practice both reflects and reaches back into the broader values of contemporary society. From popular books on self-help to the individual therapies for resilience, the messages of positive psychology, exemplified by the examples in the paper of motivational statements, have infused our everyday understandings of who we are, what we might become and our own responsibility for determining our own well-being.

Medical humanities, having a particular interest in the complex and situated relations of emotions, affects, cognitions and physical processes, has a close relationship with the discipline of psychology. At a time when policy communities are re-emphasising a positive notion of health and health promotion, alongside well-being and happiness, the interdisciplinary skills of medical humanities make the field well equipped to examine how these principles are interpreted and translated into practice. Friedli and Stearn provide an excellent example of the ways in which the tenets of positive psychology, with their attention to the internal management of attitude rather than the external influences on opportunities, correspond with a neoliberal politics in which both reflect and inform the management of unemployment. The paper advances critical medical humanities in demonstrating how a process of medicalisation reaches into diverse domains, in this case into that of welfare practices, how such medicalisation prescribes a more tightly constrained set of acceptable attitudes and behaviours and how these processes constitute an effective neoliberal politics of the personality. Most specifically, the paper draws critical attention to the power exercised by psychology, particularly positive psychology, within the disciplinary technologies of modern governance. The emergence of a narrowing of the definition of personality restricts both human rights and collective potential and makes positivity performative in its construction as the desirable attitude of our times; none of these would seem to bode well for the generation of either personal or collective understanding of wellbeing as an avowed policy outcome.

\section{Competing interests None.}

Provenance and peer review Not commissioned; internally peer reviewed.

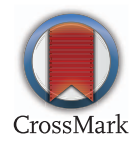


To cite Atkinson S. Med Humanit 2015;41:48-49.

Received 11 March 2015

Accepted 17 March 2015

\section{(5) Linked}

- http://dx.doi.org/10.1136/medhum-2014-010622
Med Humanit 2015:41:48-49.

doi:10.1136/medhum-2015-010701

\section{REFERENCES}

1 Friedli L, Stearn R. Positive affect as coercive strategy: conditionality, activation and the role of psychology in UK government workfare programmes. Med Hum 2015;41:40-7.
2 Office for National Statistics, UK (ONS) Measuring national wellbeing. http://www.ons.gov.uk/ons/ guide-method/user-guidance/well-being/index.html

3 Atkinson S. Moves to measure wellbeing must support a social model of health. BMJ 2011;343:d7323. 16 November 1051.

4 WHO. European health report, 2012: charting the way to well-being. Copenhagen: WHO Regional Office for Europe, 2013. http://www.euro.who.int/en/ data-and-evidence/european-health-report-2012 